\title{
Why Are Scholarly Journals Costly even with Electronic Publishing?
}

\author{
by \\ Dr. Golnessa Galyani Moghaddam \\ Assistant Professor, Dept. of Library and Information Science, Shahed University, \\ Teheran, IRAN. E-mail: g_galyani@yahoo.com
}

\begin{abstract}
:
Journal literature has long played a prominent role in the scholarly communication chain. In recent decades, however, the scholarly communication system has been facing a crisis due to the ever-escalating costs of journals. This paper examines the reasons for the high costs of scholarly journals. A brief review of literature on journal publishing costs was carried out. The paper focuses on the economics of scholarly English language journals published mainly in the United States and Europe, but which are sold worldwide, largely to academic and research libraries. Two of the features of the journal publishing industry cited a decade ago and still valid today are a "lack of competition" and "perverse incentives." The "first-copy cost" is reported to be the main reason for high journal prices both in print and electronic publishing.
\end{abstract}

Keywords- Journal Publishing, Journal Price, First Copy Cost, Electronic Publishing

\section{Introduction}

The journal has played a central role in the scholarly communication system for over three hundred years. In the past thirty years, however, this system has been facing a crisis-the "serials crisis"-due to escalating journal prices. Various groups of stakeholders, including publishers, libraries, and researchers, are concerned about these increases, which have increased faster than library budgets, causing fewer readers to have access to the journals they need. The spiraling costs themselves would be difficult enough for libraries to accommodate; at the same time, however, journal offerings have expanded rapidly in the last 20 years. A 2006 UK report on scholarly journals publishing estimated that approximately 20-25,000 peer-reviewed scholarly journals were being published worldwide. Moreover the number of these journals has grown at an average annual rate of $3-4 \%$ for the past 100 years. The report estimated that $60 \%$ percent of all journals are published online, most with parallel print editions; this figure is reported to 
be as high as $90 \%$ for English language journals from publishers in the US and UK. Roughly $10 \%$ of peer-reviewed scholarly journals are published under some form of open access model. (UK Scholarly Journals: 2006 Baseline Report, 2006). Therefore, we considered the following basic business models:

- subscription based print journals;

- subscription based electronic journals; and

- open access journals

This paper examines the reasons for the high journal costs. It will focus on the economics of scholarly English language journals published mainly in the United States and Europe, but which are sold worldwide, largely to academic and research libraries.

\section{Ambiguity in Journal Costs}

In the literature review, we are faced with a variety of terms and definitions for the cost of journals and some terms tend to be used ambiguously. For example, many articles refer to 'journal costs' when discussing library purchase costs (i.e. the price paid for journal subscriptions). While the intent is clear, it would be useful to distinguish journal publishing costs from the cost to libraries for purchasing journals. Even here, 'library journal costs' nearly always refer to the price paid, ignoring the costs of journal processing, maintenance, and use costs, (King, et al, 2004; Schonfeld, et al, 2004).

In addition, some writers use 'journal publishing costs' and 'price' synonymously. While journal prices can reflect the publication cost, they are not necessarily the same; in the majority of cases, publishers seek to make a profit/surplus. Prices may also reflect the demand for a journal, rather than simply its costs plus a fixed profit/surplus margin. Thus, high-demand journals are able to charge a higher price, because demand is less sensitive to price, (King, 2007).

These ambiguities are made worse by the prevalence of Big Deals; these make identifying a price for a specific journal very difficult if not impossible.

In a recent research study in the UK, 'acquisition price', 'incurred costs', 'cash' or 'non-cash' costs have been applied. 'Acquisition price' refers to the price paid by UK 
libraries and other organizations buying journals/articles. 'Incurred costs' refers to the total costs of publishing, distribution and access activities incurred by value chain participants, most notably, publishers and subscription agents, but excluding the acquisition price. Incurred costs can be either 'cash' or 'non-cash' costs (Cambridge Economic Policy Associates Ltd. 2008).

One of the most comprehensive literature reviews regarding journal pricing has been carried out by Donald King. He categorises journal publishing costs as fixed, variable, marginal, and average costs. The 'fixed cost' refers to the total article processing costs of manuscript processing, editing, review, etc., which are fixed in that they remain the same regardless of the circulation of a journal (i.e. number of subscriptions); some components of these costs may, of course, vary with the number of articles or even with their length. 'Variable cost' is used to refer to costs that vary with the number of subscriptions, such as the cost of reproduction (or printing), subscription maintenance and mailing of paper journals, or subscription maintenance of electronic journals. The 'marginal cost' or 'incremental cost' in this case is the variable cost of one additional subscription (King, 2007).

His review also showed a wide range of figures for publishing costs and average costs per subscription and per article (See Table 1). As this is a general paper on the journal publishing industry we will focus mainly on the first copy cost.

Table 1: Average costs - print, electronic-only, and print-plus-electronic journals compared

\begin{tabular}{|c|c|c|c|}
\hline No. of subscriptions & Print-only cost (\$) & $\begin{array}{c}\text { Electronic-only cost } \\
(\$)\end{array}$ & $\begin{array}{c}\text { Print-plus-electronic } \\
\text { cost }(\$)\end{array}$ \\
\hline 500 & 950 & $1,012.50$ & 1,050 \\
\hline 5,000 & 140 & 112.50 & 150 \\
\hline 50,000 & 59 & 22.50 & 60 \\
\hline
\end{tabular}

King notes that journals prices vary dramatically and that most of these disparities in the literature have been reported by librarians: 
"There is no question that journal prices vary dramatically; most commentary about price disparities is made from the perspective of librarians. Numerous articles discuss the prices paid by libraries, the escalating increase in prices, and 'value for money factors' based on the price paid (often referred to as journal cost), size of the journal, and citation impact factor. While those perspectives are useful, they do not begin to address the question of why journals are priced the way they are and why prices vary so much among journals" (King, 2007).

Finally, we should keep in mind that differences in the prices between different studies can be attributed to the different sampling methods, or to the methodology.

\section{Characteristics of the Journal Publishing Industry}

While scholarly journals have shown remarkable stability for over three centuries, they have what may be considered strange economics. Ten years ago Andrew Odlyzko discussed some important issues relating to the journal publishing industry that are still relevant today. Odlyzko believed that one of the most important features of scholarly publishing was the lack of price competition and this was the reason for the wide variation in journal prices among publishers, (Odlyzko, 1998).

The great disparity in costs among journals shows that the industry has not had to worry about efficiency and true price competition. The lack of effective price competition in turn has led to large profits. Logically, one would think that the consequence of high profits would be to attract a mixture of competition and innovation, which then would reduce those profits; this has not occurred. However, although commercial publishers have enjoyed increased profits in recent years, they have not been as high for not-forprofit publishers. A 2003 report on a study in Publishers Weekly stated, "While many university libraries face severe budget cuts, large commercial publishers in the academic journal market have enjoyed increasing profits. In 2002, for instance, revenue rose $26 \%$ and operating profit increased to $25 \%$ for Elsevier, the largest journal publisher in the science, technology, and medical field" (Sales and Earnings Improve at Reed Elsevier, 2003). If anything the situation has become worse with library cuts more severe and 
commercial profits increasing with Elsevier, for example, showing a further increase of $21 \%$ in 2009 over 2008.

Odlyzko also addressed some misleading ideas regarding the industry and discussed the "perverse incentives" in scholarly publishing. In general, scholars determine what journals they wish their work to appear in, and thus the cost to society to publish their work. However, scholars have no true incentive to care about such costs. What matters most to them is the prestige of the journals their work appears in (often, it must be said, because of university promotion and tenure considerations). These journals are frequently high-cost outlets. A secondary consideration for authors is ensuring that their papers are widely available. As Odlyzko points out, this factor has seldom played a major role for commercial publishers, and the availability of preprints electronically has, to some extent, addressed this factor, (Odlyzko, 1998). In addition, the growth in the number of institutional repositories worldwide in recent years should ensure wide access to today's research within the next few years.

Publishers of scholarly journals are found in both the for-profit and not-for-profit sectors of the economy. Historically, not-for-profit (or "society") publishers were the first publishers of scholarly journals. The postwar science boom in the second half of twentieth century, especially after the 1960s, led to competition among scholars to publish their research in key journals. Society publishers soon faced the problem of having to reject good manuscripts and to delay publication of accepted manuscripts because both their journals and their ability to subsidize the publication of their members' research were limited. Commercial publishers seized the opportunity to offer researchers new outlets for their manuscripts by publishing new journals in all fields, (Walker, 1998).

Today the dominant publishers of scholarly journals are multinational companies, although a large number of learned societies are involved in the market. The industry is, therefore, divided into a few large commercial publishers and many small society publishers. Commercial publishers publish large numbers of journals for profit. Society publishers publish much smaller numbers of journals (often a single journal) and do so for the benefit of their members on a not-for-distributed-profit basis. A study by this author showed that the number of scholarly electronic journals published by for-profit publishers is significantly higher than not-for-profit publishers, (Galyani, 2007a). 
Crow (2006) also described the characteristics of scholarly publishing as follows:

"The vast majority of society publishers run very small journal publishing operations. The small size and limited capacity of these operations place them at a disadvantage relative to larger publishers in terms of market leverage, business expertise, access to capital, and competitive response. Individually, small societies enjoy little market presence when disseminating their content, rendering it difficult for them to compete effectively in a rapidly changing, highly competitive, subscription-driven market. The consolidation of large commercial publishers, and the cumulative effect of their pricing and bundling practices, has led to decreased market access for society publishers. Large commercial publishers, controlling thousands of journal titles, exercise greater market power than individual small societies publishing one or two journals. The effect of this imbalance becomes more pronounced in an online distribution environment where large electronic journal bundles absorb a disproportionate share of acquisitions budgets."

One of the defining characteristics of the journal publishing industry today is the merger of publishers as several significant mergers have occurred in recent years. Mergers, and the purchase of publishers, consolidate more and more content in the hands of fewer and fewer firms, thus increasing their market share. Another method employed by commercial publishers as they strive for market dominance is the acquisition of existing journals from societies and independent editorial boards, which increases the number of titles under commercial ownership. Both of these practices have been shown to exacerbate already high price increases. One of the significant mergers of this decade was the purchase in 2001 of Harcourt General by Reed Elsevier. This transaction brought over 400 additional scientific, technical, and medical titles under the control of Elsevier Science, already the largest publisher of scientific journals in the world with a portfolio of about 1200 titles, (McCabe, 2004). Later, in 2003, Academic Press merged with Elsevier, and its journals became available through ScienceDirect. In 2007, the number of scholarly electronic journals being published by Elsevier increased to 2,220 titles, guaranteeing its position as the largest publisher of journals in the world. Kluwer 
Academic Publishers merged with Springer in September 2003, and its journals became available through SpringerLink. The most recent major merger has been that of John Wiley with Blackwells in 2006. Librarians have long opposed publisher mergers and acquisitions, believing that they lead to substantial price increases.

Nevertheless, the principles of journal publishing do not differ greatly between the commercial and not-for-profit sectors. Moreover, in addition to producing their own journals, many commercial publishers publish on behalf of learned societies. It should be noted here, however, that although commercial and not-for-profit publishers follow somewhat similar principles, the prices charged for journals differ greatly between the commercial and not-for-profit sectors. A previous study by this author revealed a remarkable difference between the commercial and nonprofit/university publishers in terms of journal prices. In 2003, the average subscription price of journals from commercial publishers was 2.8 times higher than the average subscription price of journals from not for profit/university publishers, and the average subscription price per issue of commercially owned journals was 1.8 times higher than not for profit, (Galyani, 2007b).

Although the above study proved that there is a remarkable difference between the prices that for-profit/commercial publishers charge libraries for scholarly journals and the prices that non-profit/society publishers and university presses charge this price difference does not appear to reflect a difference in quality as measured by the number of recorded citations to a journal/impact factor and the use of the journal. A case study of scholarly electronic journal usage in India showed that researchers at the Indian Institute of Science prefer to use scholarly journals that are being published by non-profit/society publishers, (Galyani, 2006). Some other studies also showed similar results. For example, in "Free Labor for Costly Journals?", Bergstrom reported on a price comparison of economics journals from non-profit and commercial publishers. The results showed that the six most-cited economics journals listed in the Social Science Citation Index were all non-profit journals and the library subscription prices for these journals averaged about $\$ 180$ per year, (Bergstrom, 2001).

Finally it must be mentioned that electronic publishing and the concomitant shift toward online publication have had a great impact on journal publishing in the last ten 
years and have enabled a substantial consolidation of the industry to take place. All this has required significant investments in electronic services and electronic delivery, something not necessarily apparent to many customers.

\section{The First-Copy Costs}

Since they were first introduced, scholarly electronic journals have been well accepted by the research community. There are two types of electronic journals published today-journals that are published in simultaneous (or almost simultaneous) print and electronic editions, and true electronic journals that are "born digital." In both cases, but especially in the latter, a key question must be taken into consideration: can electronic publications be produced at much lower costs than print journals?

Many publishers argue that costs cannot be reduced much, even with electronic publishing, since most of the cost is the first-copy cost of preparing the manuscripts for publication, (Odlyzko, 1998). Garson, (1996) observed that, for the American Chemical Society, $80 \%$ of the production cost is for the first copy (that is, a fixed cost) and $20 \%$ relates to distribution (that is, a variable cost), whether print or electronic.

First-copy costs are those that are required to produce a single issue and are independent of the number of subscribers. For an academic journal, first-copy costs include the cost of managing an editorial office-primarily wages and secretarial support for editors who handle, evaluate, and comment on the papers that authors submit—and the costs of copy-editing and typesetting. Marginal subscriber costs include the cost of printing and paper, shipping and postage, and the costs of managing subscriptions (Bergstrom, 2001).

In August 2007, the Research Information Network (RIN) commissioned Cambridge Economic Policy Associates (CEPA) to carry out a study to investigate the costs and funding flows of the scholarly communications process in the UK. The results showed that "the global cost of publishing and distributing articles is $£ 6.4 \mathrm{bn}$. The fixed first copy costs (including $£ 1.9 \mathrm{bn}$ in non-cash costs for peer review) are $£ 3.7 \mathrm{bn}$. The variable and indirect costs, and the generation of surpluses by publishers is $£ 2.7 \mathrm{bn}$. Academic institutions meet about 53\% of global publishing and distribution costs in the 
form of library subscriptions, and a further $23 \%$ in the form of the unpaid costs of peer review. Non-academic subscriptions meet about $11 \%$ of global publishing and distribution costs. The average total publishing and distribution costs per article amount to about $£ 4,000$." (Cambridge Economic Policy Associates Ltd., Full Report, 2008).

Tenopir and King have provided a comprehensive overview of the economics of journal production. According to their estimates, the first-copy costs per academic article are between $\$ 2,000$ and $\$ 4,000$. The bulk of these costs are labor costs, mostly for managing the submission, review, editing, and typesetting; and setup costs, (Tenopir and King, 1996). Based on a small survey of publishers, Robert Ubell observed that $70 \%$ of publishing costs actually relate to production of the first copy and are therefore fixed. Besides general administrative expenses, he includes in these costs marketing expenses and sales, (Ubell, 1996).

A recent survey of ten publishers produced first-copy costs ranging from $\$ 420$ to $\$ 2,500$ per article. This study asked the publishers to report their staff and purchase costs for refereeing, rewriting, copy editing and proof reading, and also typesetting, design and layout, (Dryburgh, 2002). King, Tenopir and Clarke (2006) found that Pediatrics, a journal serving about 50,000 American Academy of Pediatrics members, has a first-copy cost of $\$ 4,900$ per article (resulting in an average first-copy cost of $\$ 0.33$ per reading). The total cost per article, including print and electronic distribution, was double that amount.

In their book Towards Electronic Journals, Tenopir and King (2000) analyzed the scholarly journal publishing industry and the influences upon it that affected subscription costs. They believed that many activities were common to both electronic and paper publishing. Electronic journals can, however, save in reproduction and distribution and certain other costs such as journal covers. While electronic production and distribution costs may be much lower than the corresponding paper costs, production and distribution account for a small percentage of the total costs of low-circulation journals; a higher circulation is needed for savings to become substantial. The authors noted that prices of scientific journals (adjusted for inflation) had risen 260\% between 1975 and 1995. The number of subscriptions, especially personal subscriptions, fell precipitously as 
subscription prices rose. The fixed cost portion of a journal's total costs increases as the number of subscribers decreases. Since nearly $60 \%$ of scientific journals have fewer than 2,500 subscribers, fixed costs dominate the cost picture for most journals. The authors calculated that the total cost per average journal subscription ranges from $\$ 70$ for a journal with 10,000 subscribers, to $\$ 775$ for a journal with only 500 subscribers. They also calculated "cost per subscription," that is, the minimum price necessary to recover all costs associated with publishing a scholarly journal based on the number of subscribers. Commercial publishers were at the top of these averages. They have the highest cost per subscriber (\$441) and the highest average journal price (\$487).

While studies have pointed to first-copy paper or paper-plus-electronic production costs per article in the \$4,000-\$5,000 range,(King, 2007), (Odlyzko,1998), the current experience that Scholarly Exchange has had with its hosted electronic-only journals points to dramatically lower costs.

"Recall that neither authors nor reviewers nor editors (in most cases) contribute directly to the costs. There are minimal costs in the range of several dollars for the preparation and delivery of a reviewer-acceptable PDF document. There are similar costs for the final display and formatting of a PDF. Per-article costs for optional professional copy editing (after author-provided copy-edited text) and conversion with tagging can add in the range of $\$ 50$ and $\$ 5$ respectively to the cost. The platform upon which review, production, and display occur can add anywhere from nothing to $\$ 50$ per article to the cost, depending on the platform chosen and the volume of articles processed. My estimate is that a journal with 50 articles in a year could be published for under $\$ 4,000$; double the number of articles and the cost goes up to just over $\$ 7,000$. At 250 articles a year, the cost is under $\$ 17,000$. If the journal chose not to provide copy editing or XML conversion and tagging - two of the larger costs - the totals would be $\$ 1,200, \$ 1,650$, and $\$ 3,000$ respectively", (Fisher, 2008).

\section{The experience in Iran}

It may be noted that the average cost per journal or per paper may differ in libraries as some libraries buy their scholarly journals through 'Big Deal' or 'Consortia'. To give 
an example of an Iranian background we introduce Shahed University (having 6,000 students) and its resources. Located in Tehran, the university owns a collection of 215,000 books in different languages and 135 English print/electronic journals and many more electronic only journals and data bases.

The university, on average, spent US\$230,000 for subscription to electronic journals and data bases in the last two years. The university buys (through consortia) 9,747 journal titles and other electronic resources in different fields from various publishers such as Elsevier, Emerald, Blackwell, Springer, Oxford, Athens, ERIC, ProQuest, MEDLINE, Math Sci.net, Ovid Full Text Journals, Scopus, ISI (Web of Science), IEEE, SWETSWISE, EBM Reviews.

The library, on average, spent US\$1000 for each subscription to an English print scholarly journal in 2007. As these journals absorb a high proportion of the library budget, the librarians ceased purchasing the print version of English language journals from this year. The trend is to move toward document supply on the net combined with electronic access to resources.

The library does not subscribe to 'Big Deals' as such but works through consortia. In Iran, there are two consortia: CONSIRAN has been actively working with the libraries of the Ministry of Science, Research, and Technology (MRST) and medical university libraries. By 2008, 57 universities were involved in this consortium and they are sharing online access to licensed resources through networks. Consortia have brought economy, efficiency and equality in information availability and use to Shahed University's library. The average price for a consortia-based electronic English language journal is very low; at about US\$24 per journal.

Shahed University has access not only to consortia based resources but also to resources in other institutions. For example, the university does not pay for medical electronic resources but medical e-resources are made available to its users by the Ministry of Medical Sciences and its consortia. 
The library also provided access to resources in Persian language through the Iranian networks such as Iranian Scientific Network, National Network of Iranian University \& Research Centers Libraries, Namaye (Iranian Full Text Journals), INLM (Iranian National Library of Medicine), RICeST (Regional Information Center for Science \& Technology) and Islamic Science Citation Database (ISC).

The university has 21 experienced librarians who serve the students and staff. The average wage of a librarian is almost $\$ 500$ per month which illustrates the heavy cost of purchasing English language material. However the average price for annual subscription of Persian journals is very cheap in comparison with English language journals; for example, the average price of a Persian scholarly journal with 4 issues a year is $\$ 10$. Therefore subscription to Iranian journals absorbs a small proportion of the library budget. The same holds true for other national resources.

Students and staff can search through the library catalog (OPAC) and download whatever they needed. In addition, there is permission in licensed agreement via consortia which allows the library to print out material.

If a user requests a resource to which the library does not subscribe, there are three different methods of document delivery.

First is a document delivery service through LHL (Linda Hall Library). The librarian will contact LHL and they will provide the document within 48 hours. The user has to pay $\$ 9$ for obtaining the document.

The second is the "AMIN MODEL" which covers both document delivery and interlibrary loan services organized by the Iranian National Library. The member universities will buy coupons and pay $\$ 2$ for each requested document.

The third one is called "IRANICA". This is an Iranian document delivery service via e-mail and the fee is $\$ 3$ per paper. The library will pay and scan the receipt for IRANICA, who will send the paper via e-mail. 


\section{The Cost of Publishing in Open Access journals}

The economics of journal publishing in the electronic environment were documented well by the end of the 1990s and held true for a few years later; however, the emergence of open access journals has caused a shift in the literature towards the economics of this model. Open access publishers tend to recover their costs via a charge for processing articles that is paid by an author's institution or funding agency-hence the "author-pays" tag for this model, (Cockerill, 2004). In the 1990s, when experts were estimating first copy cost, no attention was paid to the open access model. Now this model has challenged the traditional scenario of scholarly publishing.

One of the reasons for emerging open access models is the dissatisfaction of scholars and librarians with the market of academic journals even with electronic publishing, (McCabe and Synder, 2005). New technologies might be expected to lower the production and distribution costs of journals, and for these reduced costs to lead to reduced prices; but library subscription prices remain high, (Bergstrom, 2001) and indeed have continued to rise faster than inflation, (McCabe, 2002). This dissatisfaction has led to the proposal for a new business model based on open access for academic journals. In contrast to a traditional journal, which generates most of its revenue with subscription fees, an open access journal makes its articles available freely, generating revenue with author fees. Being freely available inevitably leads to the shifting of the financial burden from the end-users of open access information, such as readers and libraries, to the authors, libraries and research organisations etc who fund the process. In the website of open access journals (http://open-access.net/de_en/homepage/) different publication fee models are described as follows:

\section{Variant 1: author pays}

In this business model, financing takes place at the beginning of the publishing process by charging the author a publication fee (also known as an article-processing charge or APC). Although the publication fee is frequently borne by the author's research funder or employer, such financial support is not always available. 


\section{Variant 2: research funder subsidises}

In this model, research funders subsidise author publication fees.

\section{Variant 3: institutional membership}

Some open access publishers such as BioMed Central and PLoS offer academic and research institutions institutional membership. The fee depends on the membership level chosen and the size of the institution. By becoming members, institutions enable their authors to publish a certain number of articles per year free of charge or at a reduced fee in the journals operated by the publisher in question. For example, since 2008 the fees for the articles which Max Planck Society (MPS) researchers publish in PLoS journals have been covered by the society's institutional membership. Because many open access publishers now offer institutional membership, an institution may have several, especially if it wishes to offer its authors as much freedom of choice as possible.

\section{Variant 4: Publishing support funds}

In this variant, universities or research institutions reimburse the fees charged to authors by open access journals from a fund established especially for this purpose. This business model is currently being tested by Bielefeld University Library (UB) in a pilot programme which runs until the end of 2009. The idea is to prevent authors being put off publishing their work in an open access journal because of the costs involved. Authors who do not have access to other funds such as publication allowances from research funders can apply for a grant from the Bielefeld UB fund. This is especially important for junior scientists and scholars who are less likely to have funding of their own.

A study carried out by the Kaufmann-Wills Group (2005) revealed that contrary to what many believed before the study, over half of all fully Open Access journals $(52 \%)$ do not in fact charge any sort of author-side fees.

Over $40 \%$ of the open access journals are not yet covering their costs and, unlike subscription journals, there is no reason why the passage of time - evidenced in 
increasing submissions, quality or impact - should actually change that; their financial future therefore seems somewhat uncertain. Indeed, a surprising number of the open access publishers made comments which suggested that financial sustainability was not high on their list of priorities, (Kaufmann-Wills Group, 2005).

The result of a study in Spain showed that many authors are not willing to pay an author fee for publishing in an open access journal and they noted that lack of funds was a significant barrier to open access publishing, (Hernández-Borges et al., 2006).

There has been much literature relating to open access journals since 2000, though it should be pointed out that, although rising, only $10 \%$ of peer-reviewed scholarly journals were published under some form of open access model in 2005/06, (UK Scholarly Journals: 2006 Baseline Report, 2006). More recently the Directory of Open Access Journals (DOAJ) recorded 3960 open access journals in March 2009 compared with the core number of 25,000 peer reviewed scholarly journals in the world. It may be noted that DOAJ lists only 1416 open access journals that are searchable at article level and the nature of the quality control or peer review of some of them is controversial.

While open access models are interesting and make research permanently visible and accessible, we should not forget that a large number of scholarly journals are still being publishing by commercial and non-for-profit publishers and are not accessible to all. In addition, it is too early to draw any firm conclusion about the future of open access model as stakeholders have not yet solved all the business issues. The awareness and acceptance of open access publishing is also addressed in the literature and a review of studies shows that we still need some cultural and systematic changes toward open access publishing and its value. The result of a recent study in US was amazing:

"If you offer something of value to people for free while someone else charges a hefty sum of money for the same type of product, one would logically assume that most people would choose the free option. According to new research in today's edition of the journal Science, if the product in question is access to scholarly papers and research, that logic might just be wrong. These findings provide new 
insight into the nature of scholarly discourse and the future of the open source publication movement" (US Federal News Service, 2009).

The above study revealed that on average, when a given publication was made available online after being in print for a year, being published in an open source format increased the use of that article by about $8 \%$. When articles are made available online in a commercial format a year after publication, however, usage increases by about $12 \%$, (US Federal News Service, 2009).

\section{Conclusion}

High journal prices in the last 30 years have led to a crisis in scholarly communications. One of the reasons for spiraling journal costs is the economics of the journal publishing business. High journal prices may be considered an indicator of an inefficient market. A "lack of competition" and "perverse incentives" have led to rapidly rising prices in the last 30 years. These two key issues are still relevant to some extent with online publishing. The shift to electronic publishing has been driving the journal publishing industry towards a considerable consolidation as it has required significant investments in electronic services and electronic delivery. On the other hand, publishing through open access models and electronic publishing are two ways which are challenging the traditional economics of scholarly journal publishing.

There is little difference between for-profit and non-for-profit publishers in the principles of journal publishing, but there are significant differences between the prices they exact from libraries. Publishers continue to claim that the main reason for the high price of journals even in today's electronic environment is the "first-copy cost,". Scholarly electronic journals are costly to produce but cheap to reproduce, which means that the costs of production are dominated by the first-copy costs. A production facility and distribution server must be in place in order to take advantage of the low costs of distribution. For a typical scholarly journal, most of the costs to be recovered by the producer are fixed. Finally, while the issues of first-copy costs and high production costs

of established scholarly journals have remained unresolved with electronic publishing, 
the author believes that the economics issues of traditional scholarly journals need to be investigated further by researchers in the digital environment.

\section{Acknowledgement:}

The author wishes to thank Jim Cole, Iowa State University, Ames, Iowa 50010-2140, USA, and Mike McGrath, Editor of Interlending \& Document Supply, for their assistance in editing the text of this paper.

\section{References}

Bergstrom, Theodore C. 2001, Free Labor for Costly Journals. URL: http://www.econ.ucsb.edu/ tedb/Journals/jeppdf.pdf [Viewed March 30, 2007]

Cambridge Economic Policy Associates Ltd. 2008,

"Activities, costs and funding flows in scholarly communications" Full Report, URL: http://www.rin.ac.uk/costs-funding-flows. [Viewed January 24, 2009]

Cockerill, Matthew. 2004, The Benefits to Scientists Of Open Access Scientific Publishing Provided by the Internet Are Too Significant to be Ignored. Financial Times (November 26). London (UK), p.13.

Crow, R. 2006, Publishing Cooperatives: An Alternative for Society Publishers. URL: http://www.arl.org/sparc/bm doc/Cooperatives_v1.pdf. [Viewed March 20, 2007]

Dryburgh, A. 2002, The Costs of Learned Journal and Book Publishing: A Benchmarking Study for ALPSP. Association of Learned and Professional Society Publishers. September.

Fisher Julian H. 2008, Scholarly Publishing Re-invented: Real Costs and Real Freedoms. Journal of Electronic Publishing, Spring. URL:http://quod.lib.umich.edu/cgi/t/text/textidx?c=jep;cc=jep;q1=Fisher;op2=and;op3=and;rgn=main;view=text;idno=3336451.0011.204 [Viewed January 10, 2009]

Galyani Moghaddam, G. 2006, Price and Value of Electronic journals: A Survey at the Indian Institute of Science. Libri: International Journal of Libraries and Information Services. Vol. 56 No 2, June. pp. 108-116.

Galyani Moghaddam, G. 2007a, Archiving Challenges of Scholarly Electronic Journals: How do Publishers Manage them?. Serials Review, Vol. 33 No. 2, June, pp. 81-90.

Galyani Moghaddam, G. 2007b, Scholarly Electronic Journal Publishing: A Study 
Comparing Commercial and Nonprofit/University Publishers. The Serials Librarian, Vol 51 No 3/4, pp 165-183.

Garson, L.R. 1996, Can e-journals save us? A publisher's view. In the Proceedings of the Conference 'Challenging Marketplace Solutions to Problems in the Economics of Information'. Washington, DC, 18-19 September 1995 (ed. By M. E. Butler and B. R. Kingma). Washington, D.C., Association of Research Libraries, pp. 99-107.

Hernández-Borges, Angel A., Cabrera-Rodríguez, Raul., and Abián Montesdeoca-Melián; B. 2006, Awareness and Attitude of Spanish Medical Authors to Open Access Publishing and the "Authors Pays" Model. Journal of the Medical Library Association, October, Vol 94 No 4, pp.449-451.

King, D.W. 2007, The Cost of Journal publishing: A Literature Review and Commentary. Learned Publishing, April, Vol 20 No 2, pp 85-106.

King, D.W., Tenopir, C. and M. Clarke. 2006. Total Reading of Journal Articles. D-Lib $\begin{array}{llllll}\text { Magazine } & \text { (October), } & \text { Vol } & 12 & \text { No } & 10 .\end{array}$ http://www.dlib.org/dlib/october06/king/10king.html [Viewed March 15, 2007]

King, D.W., Aerni, S., Brody, F., Herbison, M., and Kohberger, P. 2004, Comparative Cost of the University of Pittsburgh Electronic and Print Library Collections. Pittsburgh, Sara Fine Institute for Interpersonal Behavior and Technology. URL: http://crash.exp.sis.pitt.edu/sfi/documents/sfi-pub20040405a.pdf . [Viewed December 10, 2008]

Kaufman-Wills Group, LLC. 2005, The Facts about Open Access: A Study of the Financial and Non-financial Effects of Alternative Business Models for Scholarly Journals.URL: http://www.alpsp.org/ngen public/article. asp?id=200\&did=47\&aid=270\&st=\&oaid=-1

[Viewed January 10, 2009]

McCabe, Mark J. 2002, Journal Pricing and Mergers: A Portfolio Approach. The American Economic Review, Vol 92 No 1, pp. 259-269.

McCabe, Mark J. 2004, Law Serials Pricing and Mergers: A Portfolio Approach. (accepted for publication in the B.E. Journals in Economic Analysis and Policy, subject to minor revisions).

McCabe, Mark J., Snyder, Christopher M. 2005, Open Access and Academic Journal Quality. The American Economic Review, May, Vol 95 No 2, pp. 453-458.

Odlyzko, Andrew. 1998, The Economics of Electronic Journals. The Journal of Electronic Publishing (September), Vol 4 No 1. 
Sales and Earnings Improve at Reed Elsevier. 2003, Publishers Weekly (March 3), 250(9): 28.

Schonfeld, R.C., King, D.W., Okerson, A, and Fenton, E.G. 2004, The Non subscription Side of Periodicals: Changes in Library Operations and Cost between Print and Electronic Formats. Washington, DC, Council on Library and Information Resources. Available at: http://www.clir.org/PUBS/reports/pub127/pub127.pdf . [Viewed December 10, 2008]

Tenopir, C. and D.W. King. 1996, Setting the Record Straight on Journal Publishing, Myth vs. Reality. Library Journal, Vol 5 No 121, pp 32-34.

Tenopir, C. and D.W. King. 2000, Towards Electronic Journals: Realities for Scientists, Librarians, and Publishers. Washington, D.C., Special Libraries Association.

Ubell, Robert. 1996, Cost Centers and Measures in the Networked Information Value Chain. Spring Meeting of the CNI Task Force. URL: http://www.cni.org/projects/costcenters/ [Viewed March 12, 2007]

UK Scholarly Journals: 2006 Baseline Report. 2006, URL: http://www.rin.ac.uk/files/Executive\%20Summary.pdf. [Viewed April 2, 2007]

US Federal News Service, Including US State News. 2009, Open Access to Scientific Papers may not Guarantee Wide Dissemination. Washington, D.C.: February, 25.

Walker, T. J. 1998, Free Internet Access to Traditional Journal. American Scientist, Vol. 86: 463-471. 